\title{
A highly immunogenic putative Mycobacterium kansasif lipoprotein
}

\author{
Geraldo R. G. Armoa, † David A. Rouse, Jaygopal Nair, $\ddagger$ Julia C. Mackall \\ and Sheldon L. Morris
}

Laboratory of Mycobacteria, Center for Biologics

Evaluation and Research, Food and Drug

Administration, 8800

Rockville Pike, Bethesda, MD 20892, USA

\author{
Author for correspondence: Sheldon L. Morris. Tel: +1 301496 5517. Fax: +1 3014022776. \\ e-mail: smorris@helix.nih.gov
}

\begin{abstract}
The resurgence of tuberculosis, the emergence of multiple drug resistant tuberculosis, and the increasing prevalence of mycobacterial disease in AIDS patients have increased the importance of defining new mycobacterial antigens that can be utilized in the development of improved diagnostic reagents and more effective vaccines. In this report, a highly immunogenic Mycobacterium kansasif protein (MK35) and the gene encoding this antigen were characterized. MK35 gene probes reacted with genomic DNA from $M$. avium, $M$. bovis BCG, $M$. intracellulare and $M$. tuberculosis but not with DNA isolated from nine other mycobacterial species. Nucleotide sequence analysis showed that the MK35 gene encodes a 26 kDa protein which contains a consensus bacterial lipoprotein processing sequence. In addition, detergentphase separation studies strongly suggested that MK35 is a lipoprotein. Skin test assays demonstrated that MK35 elicited a strong response in guinea pigs sensitized with $\boldsymbol{M}$. kansasii but did not react in $\boldsymbol{M}$. tuberculosis-sensitized guinea pigs. These results further suggest that mycobacterial lipoproteins are immunogenic antigens that should be considered in the development of new mycobacterial vaccines and diagnostic reagents.
\end{abstract}

Keywords: Mycobacterium kansasii, lipoproteins, mycobacterial antigens

\section{INTRODUCTION}

Mycobacterium kansasii is an environmental organism which has been isolated from soil, house dust, and tap water and had been commonly identified in western Europe and the United States (Davies, 1994). Infections with $M$. kansasii can cause a chronic, progressive, and sometimes fatal pulmonary disease in normal hosts (Lillo et al., 1990). Moreover, disease resulting from $M$. kansasii infections is extremely serious and life-threatening in patients with advanced immunosuppression (Sheerer et al., 1986; Shafer \& Sierra, 1992). Hospital-based studies have indicated that $M$. kansasii is the second most common nontuberculous mycobacterial infection of AIDS patients in the United States (Horsburgh \& Selik, 1989). In fact, two reports from hospitals in Baltimore and Los Angeles

\footnotetext{
†Present address: Oswaldo Cruz Foundation, Rio de Janeiro, Brazil.
}

¥Present address: University of Maryland Medical School, Baltimore, MD, USA.

Abbreviation: DTH, delayed-type hypersensitivity.

The GenBank accession number for the sequence reported in this paper is U20446. have concluded that $M$. kansasii was isolated more frequently than $M$. tuberculosis among their patients with documented HIV infection (Young et al., 1986; Levine \& Chaisson, 1991).

The increasing incidence of mycobacterial diseases in immunocompromised individuals and the emergence of the highly progressive and rapidly fatal multiple drug resistant tuberculosis (MDRTB) have increased public awareness about the inadequacy of current protocols to prevent and clinically manage mycobacterial infections (Dooley et al., 1992; Reilly, 1993). An improved mycobacterial vaccine is clearly needed because the current vaccine, the bacillus Calmette-Guérin (BCG), has questionable effectiveness (Fine \& Rodrigues, 1990). Colditz et al. (1994), using meta-analysis of data from relevant BCG efficacy trials, have recently concluded that the overall efficacy of BCG is only $50 \%$. More rapid and specific methods for diagnosing mycobacterial diseases are also essential for improving patient care. Current procedures for detecting and speciating mycobacterial infections, such as tuberculin skin testing and mycobacterial cultivation, are clearly inadequate. For example, because the radiographic manifestations, pathology and clinical 
features of $M$. kansasii and $M$. tuberculosis infections are similar, standard methodologies cannot rapidly distinguish between these infections (Wallace et al., 1990). The differentiation between $M$. kansasii and $M$. tuberculosis bacilli by cultivation and biochemical analysis currently requires several weeks. In an era of $M$. tuberculosis and the HIV pandemics, the failure to rapidly identify mycobacterial disease can have an important impact on the implementation of proper public health control measures.

The development of improved methods to prevent and detect mycobacterial disease in the future will probably be linked to the isolation of new mycobacterial antigens and the further characterization of previously identified mycobacterial immunogens. In this paper, we describe the identification and characterization of a putative mycobacterial lipoprotein, the MK35 protein from M. kansasii. The immunoreactivity of MK35 as demonstrated by serological studies and skin test assays further suggests that mycobacterial lipoproteins are immunodominant mycobacterial antigens.

\section{METHODS}

Preparation of mycobacterial DNA and antigens. The $M$. kansasii Bostrom strain was obtained from the culture collection at the George Washington University School of Medicine. The following mycobacterial strains were obtained from the American Type Culture Collection (Rockville, MD, USA): $M$. asiaticum (25274), M. avium (35714), M. bovis (27291), M. bovis BCG (27291), M. cbelonei (19977), M. fortuitum (6841), M. intracellulare (13950), M. marinum (927), M. phlei (11758), M. scrofulaceum (19981), M. smegmatis (14468), M. terrae (15755), M. tuberculosis H36Ra (25177), M. tuberculosis H37Rv (27294), $M$. vaccae (15483) and $M$. xenopi (19250). The mycobacterial antigen preparations used in these experiments were sonic extracts of actively proliferating mycobacteria grown in Long's synthetic medium (with $1 \%, \mathrm{w} / \mathrm{v}$, glucose) at $37^{\circ} \mathrm{C}$ for three weeks. At late-exponential phase, the cells were harvested by centrifugation, washed in deionized water, sonicated and centrifuged as described previously (Rouse et al., 1990). For DNA extractions, the strains were grown in the same medium, the cells were washed, and total DNA was extracted using published protocols (Morris et al., 1988).

Production and screening of monoclonal antibody (mAb) 3869. The protocols for generating and screening antimycobacterial monoclonal antibodies have been previously described (Rouse et al., 1990). Briefly, Balb/c mice were injected intraperitoneally three times in one week with $10 \mu \mathrm{g}$ per injection of an ammonium sulfate precipitate of a sonic extract from the $M$. kansasii Bostrom strain. Sequential bleedings of these animals indicated that serum antibody levels remained high for several months. After 5 months, the immunized mice were given an intravenous booster of $1 \mu \mathrm{g}$ of the $M$. kansasii ammonium sulfate precipitate. Cell fusions were performed $3 \mathrm{~d}$ later by a modification of the method of Kohler \& Milstein (1975). All hybridomas generated were initially screened with preparative immunoblots using the Miniblotter 28 apparatus (Immunetics). To determine whether hybridomas recognized protein-associated epitopes, mycobacterial sonic extracts were digested to completion with proteinase $\mathrm{K}$ and pronase prior to the screening assay.

To evaluate the specificity of $\mathrm{mAb} 3869$, the following mycobacterial sonic extracts were resolved by SDS-PAGE: $M$. kansasii, $M$. avium, $M$. bovis (BCG), $M$. chelonei, $M$. fortuitum, $M$. intracellulare, M. marinum, M. phlei, M. scrofulaceum, M. smegmatis, $M$. tuberculosis, $M$. vaccae, $M$. xenopi and $M$. vaccae, plus Escherichia coli. Immunoblots prepared from these gels were incubated with mAb 3869 and developed as previously described (Morris et al., 1991).

Production and screening of a $\boldsymbol{M}$. kansasii $\lambda$ gt11 expression library. Preparation of the expression library was based on established protocols (Morris et al., 1988). This methodology yielded approximately $10^{6}$ individual recombinant bacteriophages. DNA restriction analyses indicated that nearly $90 \%$ of these phages contained insert fragments. Immunoreactive bacteriophages were detected with monoclonal antibodies using protocols that were utilized to identify and isolate recombinant bacteriophages from the $M$. intracellulare expression library (Morris et al., 1990).

Purification of the MK35 recombinant protein. The M. kansasii recombinant protein was overproduced using the pGEMEX system (Promega), a T7-polymerase-based expression system (Studier \& Moffat, 1986). Recombinant clones were overexpressed as described by the manufacturer with the modification that the BL21(pLysS) E. coli host strain was substituted for the manufacturer's recommended host strain. Specifically, bacteriophages expressing a recombinant antigen recognized by $\mathrm{mAb} 3869$ were purified using LambdaSorb phage absorbent as described by the manufacturer (Promega). The mycobacterial insert fragment was isolated from low-melting-point agarose after EcoRI digestion and cloned into the PGEMEX vector. The ligation mixtures were then transformed into BL21 ( $\mathrm{pLys} S$ ). The $M$. kansasii antigen was overexpressed by first growing the recombinant pGEMEX BL21 transformants at $37^{\circ} \mathrm{C}$ to an $\mathrm{OD}_{600}$ of 0.5 in LB medium supplemented with $30 \mu \mathrm{g}$ chloramphenicol ml$l^{-1}$ and $100 \mu \mathrm{g}$ ampicillin $\mathrm{ml}^{-1}$. The cells were induced with $5 \mathrm{mM}$ IPTG and incubated with aeration for an additional $3-4 \mathrm{~h}$ at $37^{\circ} \mathrm{C}$. After the induction period, the cells were centrifuged, resuspended in 0.05 vol. $50 \mathrm{mM}$ Tris (pH 7.4), $2 \mathrm{mM}$ EDTA, $150 \mathrm{mM} \mathrm{NaCl}, 2 \mathrm{mM}$ phenylmethylsulfonyl fluoride (PMSF) and frozen at $-70^{\circ} \mathrm{C}$.

The BL21 lysates containing the overexpressed MK35 protein were resolved using standard SDS-PAGE techniques. To visualize the separated proteins, the gels were then soaked in a fluorescent dye solution that had been prepared by diluting $1 \mathrm{ml}$ of a stock solution (10 mg ml $\mathbf{~ m}^{-1}$ in methanol) of 3,3'-dipentyloxacarbocyanine iodide (Molecular Probes) in $100 \mathrm{ml} 0.1 \mathrm{M}$ $\mathrm{NaHCO}_{3}, 0.1 \%$ SDS. After $10 \mathrm{~min}$, the gels were destained in water for another $10 \mathrm{~min}$. The gels were exposed to UV illumination and the overexpressed protein band was excised from the gels. The recombinant protein was electroeluted from the acrylamide slices using the Elutrap System (Schleicher and Schuell). Electroeluted $M$. kansasii recombinant protein was precipitated with $50 \%$ saturation ammonium sulfate, resuspended in $10 \mathrm{mM}$ sodium phosphate $(\mathrm{pH} \mathrm{7.0)}$ and dialysed against the same buffer at $4{ }^{\circ} \mathrm{C}$. Eluted recombinant protein was purified by hydrophobic interaction chromatography on a Hewlett Packard 1090 series M liquid chromatograph equipped with a photodiode array detector. The column used was a Hewlett Packard phenyl 5PW $(75 \times 7.5 \mathrm{~mm})$ equilibrated with

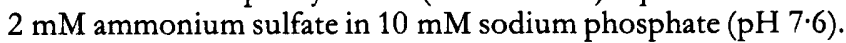
Protein solutions were adjusted to $2 \mathrm{M}$ ammonium sulfate and were filtered through a $0.45 \mu \mathrm{M}$ filter before injection. Protein was eluted with a $15 \mathrm{~min}$ gradient from $2 \mathrm{mM}$ ammonium sulfate in $10 \mathrm{mM}$ sodium phosphate $(\mathrm{pH} \mathrm{7.6)}$ to $10 \mathrm{mM}$ sodium phosphate. The flow rate was set at $0.5 \mathrm{ml} \mathrm{min}^{-1}$. Protein peaks were detected by absorbance at $280 \mathrm{~nm}$.

Skin testing with purified MK35. Hartley strain guinea pigs $(350 \mathrm{~g})$ were sensitized by injecting into the nuchal area $2 \mathrm{mg}$ of heat-inactivated bacilli from the $M$. kansasii Bostrom strain, the 
$M$. intracellulare type strain, an $M$. avium serovar 4 AIDSassociated strain, or the $M$. tuberculosis H37Rv strain. Each preparation was suspended at a $10 \mathrm{mg} \mathrm{m}^{-1}$ concentration in Drakeol 6VR prior to the sensitization. The guinea pigs were skin tested by subcutaneous injection of $3 \mu \mathrm{g}$ of the purified $M$. kansasii recombinant protein or the gene 10 protein that had been dissolved in $0.1 \mathrm{ml}$ of $0.85 \% \mathrm{NaCl}, 0.001 \%$ Tween 80 . As positive controls, $0.1 \mu \mathrm{g}$ of homologous sonic extracts were also tested in the sensitized guinea pigs. Delayed-type hypersensitivity responses were recorded $24 \mathrm{~h}$ after the recombinant protein challenge by measuring erythema at the site of injection.

Nucleotide sequence analysis of the MK35 gene. Protein expression experiments demonstrated that the entire MK35 coding sequence was located on a $1.3 \mathrm{~kb}$ EcoRI-NruI subfragment of the initial $3.3 \mathrm{~kb}$ phage insert fragment. For nucleotide sequence analysis of the MK35 gene, the $1.3 \mathrm{~kb}$ subfragment was cloned into the Bluescript SK vector. The sequence was determined utilizing double-stranded DNA sequencing protocols provided with the BstI polymerase sequencing system (Bio-Rad). The Bluescript T3 or M13 universal primers and one of several oligonucleotides generated from the $M$. kansasii sequences within the EcoRI-NruI fragment were used as sequencing primers. The $1.3 \mathrm{~kb}$ subfragment was sequenced completely and independently on both strands.

DNA hybridization studies. The DNA hybridizations were done as described previously (Nair et al., 1993). Southern blots were hybridized to the MK35 probe using reagents and protocols provided in the PHOTOGENE Detection System (Bethesda Research Laboratories). After hybridization at $42{ }^{\circ} \mathrm{C}$ for $18 \mathrm{~h}$, the blots were washed twice, 5 min per wash, in $5 \times$ $\mathrm{SSC} / 0.5 \% \mathrm{SDS}$ at $65^{\circ} \mathrm{C}$ and then twice, $20 \mathrm{~min}$ per wash, in $0.1 \times \mathrm{SSC} / 1.0 \% \mathrm{SDS}$ at $52{ }^{\circ} \mathrm{C}$. The membranes were washed for $5 \mathrm{~min}$ in $2 \times$ SSC followed by a brief wash in TBS [10 mM Tris ( $\mathrm{pH} \mathrm{7.4),} 150 \mathrm{mM} \mathrm{NaCl}$ ] supplemented with $0.05 \%$ Tween 20 (TTBS). After blocking with $3 \%(\mathrm{w} / \mathrm{v})$ bovine serum albumin (Sigma) in TTBS at $65^{\circ} \mathrm{C}$ for $1 \mathrm{~h}$, the blots were incubated in streptavidin alkaline phosphatase conjugate for $10 \mathrm{~min}$ at room temperature, and washed twice in TTBS. A final wash for $1 \mathrm{~h}$ at room temperature was performed using a solution provided by the manufacturer. The membranes were then air-dried and incubated with the detection reagent for 3.5 h. Finally, the blots were exposed to Kodak XAR-2 film and developed.

Triton X-114 phase separations. The Bostrom strain of $M$. kansasii was grown in liquid culture and sonicated as described above. Triton X-114 phase separations of the sonic extracts followed previously described protocols (Bordier, 1981; Nair et al., 1992). The protein concentrations of the separated phases were determined using the Bio-Rad protein assay. Samples were loaded at $20 \mu \mathrm{g}$ per well on to $4-20 \%(\mathrm{w} / \mathrm{v})$ polyacrylamide gels (Integrated Separation Systems), electrophoresed, and then transferred to nitrocellulose. The immunoblots were incubated with $\mathrm{mAb} 3869$ and developed as described above.

\section{RESULTS}

\section{Isolation of a recombinant bacteriophage expressing the MK35 antigen}

To identify novel mycobacterial antigens, a $M$. kansasii $\lambda g t 11$ expression library was generated and monoclonal antibodies that recognized $M$. kansasii antigens were produced. $\mathrm{mAb} 3869$ was of particular interest because immunoblot analyses demonstrated that this antibody specifically recognized $M$. kansasii sonic extract antigens

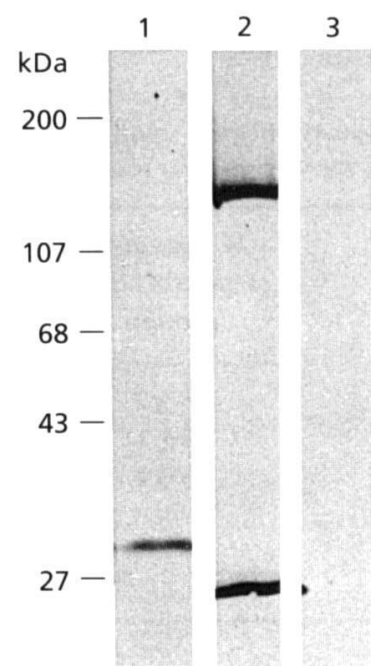

Fig. 1. Immunoblot analysis of $\lambda$ lysogen lysates containing the MK35 $\beta$-galactosidase fusion protein. Immunoblots were incubated with mAb 3869 and developed as described in Methods. Lanes: $1, M$. kansasii sonic extract; 2 , lysate of a $\lambda$ lysogen expressing the MK35 recombinant protein; 3, lysate of a $\lambda$ lysogen expressing an $M$. avium fusion protein.

and did not react with sonic extracts from 12 other mycobacterial species. Furthermore, protease sensitivity assays indicated that $\mathrm{mAb} 3869$ recognized a proteinassociated epitope. Initial immunoblot studies suggested that the molecular mass of the reactive antigen was $35 \mathrm{kDa}$ (hence its designation as MK35) (Morris et al., 1991). Subsequent immunoblot characterizations using gradient SDS-polyacryamide gels have demonstrated that the apparent molecular mass of the MK35 antigen is $32 \mathrm{kDa}$.

Since $\mathrm{mAb} 3869$ recognized a specific $M$. kansasii proteinassociated epitope, it was utilized to screen the $\lambda \mathrm{gt} 11$ library. A recombinant bacteriophage expressing an antigen detected by $\mathrm{mAb} 3869$ was identified and purified. Lambda lysogens were then generated by infecting E. coli strain 1089 with antibody-reactive bacteriophage at a permissive temperature. Two mAb 3869 reactive polypeptides with molecular masses of 150 and $25 \mathrm{kDa}$ were detected in $\lambda$ lysogen lysates by immunoblotting (Fig. 1, lane 2). In subsequent immunoblot studies, the reactivity of the $150 \mathrm{kDa}$ antigen with an anti- $\beta$-galactosidase antibody showed that this $M$. kansasii recombinant antigen is a $\beta$-galactosidase fusion protein (data not shown). The $25 \mathrm{kDa}$ peptide that reacted with $\mathrm{mAb} 3869$ is probably a breakdown product of the larger fusion protein. As controls, a lysate from an unrelated $M$. avium $\lambda$ lysogen and $M$. kansasii sonic extract was evaluated. The control $\lambda$ lysogen lysate did not react with $\mathrm{mAb} 3869$ (Fig. 1, lane 3). In contrast, $\mathrm{mAb} 3869$ recognized a $32 \mathrm{kDa}$ antigen in the $M$. kansasii extract preparation (Fig. 1, lane 1).

\section{Immunoreactivity of MK35}

To evaluate the capacity of MK35 to induce cell-mediated responses, MK35 was tested in a guinea pig delayed-type 
Table 1. Skin test reactivity of the MK35 recombinant protein

The mean skin test reaction \pm the standard deviation $(\mathrm{mm})$ for three guinea pigs is shown. NR, No reaction.

\begin{tabular}{|lcc|}
\hline $\begin{array}{l}\text { Sensitizing } \\
\text { antigen }\end{array}$ & $\begin{array}{c}\text { M. kansasii } \\
\text { recombinant } \\
\text { protein }\end{array}$ & $\begin{array}{c}\text { Homologous } \\
\text { sonic extract }\end{array}$ \\
\hline M. kansasii & $15 \pm 2$ & $12 \pm 2$ \\
M. avium & $6 \pm 1$ & $15 \pm 1$ \\
M. intracellulare & $6 \pm 1$ & $15 \pm 1$ \\
M. tuberculosis & $\mathrm{NR}$ & $15 \pm 0$ \\
Controls (not & $\mathrm{NR}$ & $\mathrm{NR}$ \\
sensitized) & & \\
\hline
\end{tabular}

hypersensitivity (DTH) assay. For these skin test assays, MK35-gene 10 fusion proteins were utilized because overexpression of these recombinant proteins facilitated their purification. The MK35-gene 10 protein and a gene 10 control antigen were purified as described in Methods. Three micrograms of the purified MK35 recombinant protein and the gene 10 control were injected intradermally into guinea pigs that had been sensitized with either $M$. kansasii, $M$. avium, $M$. intracellulare or $M$. tuberculosis, and into non-sensitized guinea pigs. Concurrent testing with $0 \cdot 1 \mu \mathrm{g}$ of homologous mycobacterial sonic extract confirmed that the animals had been properly sensitized. As seen in Table 1, the recombinant MK35 protein elicited a $15 \mathrm{~mm}$ skin test reaction in $M$. kansasiisensitized animals. In contrast, the MK35 fusion protein did not evoke a response in control non-sensitized guinea pigs. The recombinant protein also induced a moderate cross-reactive response in animals sensitized with $M$. avium complex $(6 \mathrm{~mm})$ but did not elicit a detectable response in those immunized with $M$. tuberculosis. The gene 10 control did not induce a DTH response in either control or sensitized animals. Therefore, the cell-mediated reactions elicited by the fusion protein resulted from the antigenicity of the $M$. kansasii portion of this gene 10 hybrid protein.

\section{Nucleic acid hybridization studies using MK35 gene probes}

An EcoRI-NruI fragment of the MK35 coding sequence was labelled and used to probe EcoRI-digested DNA from 12 different strains of mycobacteria. As expected, the MK35 probe hybridized strongly to a $3.3 \mathrm{~kb}$ restriction fragment in the $M$. kansasii genomic sample (Fig. 2a, lane 7). Hybridization was also detected with a $3.5 \mathrm{~kb}$ M. avium chromosomal fragment (Fig. 2b, lane 2) and a $7.5 \mathrm{~kb} M$. intracellulare fragment (Fig. 2b, lane 6) upon extended exposure. The MK35 probe weakly hybridized to a $3.0 \mathrm{~kb}$ restriction fragment present in all $M$. tuberculosis complex strains tested (Fig. 2b, lane 4).

\section{Nucleotide sequence analysis of the MK35 gene}

To facilitate characterization of the MK35 protein, the nucleotide sequence of the gene encoding it was determined. The MK35 gene sequence and deduced protein sequence are shown in Fig. 3. The sequence contains a $675 \mathrm{bp}$ open reading frame, initiating at an ATG (bp 19-21) and terminating at a TAA (bp 694-696). The open reading frame encodes a putative polypeptide of 225 amino acids with an estimated size of $26 \mathrm{kDa}$. Consistent with the high $\mathrm{G}+\mathrm{C}$ content of mycobacterial genes, the MK35 coding sequence is $66 \mathrm{~mol} \% \mathrm{G}+\mathrm{C}$, with a $87 \%$ $\mathrm{G}+\mathrm{C}$ bias in the third nucleotide of amino acid codons. A potential Shine-Dalgarno ribosome-binding site is positioned $11 \mathrm{bp}$ upstream of the initiation codon. Inverted repeat sequences that have been identified downstream of the termination codon in several mycobacterial genes and that have been postulated to facilitate transcriptional termination (Shinnick et al., 1989; Collins et al., 1990; Morris et al., 1992) were not identified in the MK35 gene sequence. The MK35 gene sequence and the (a)

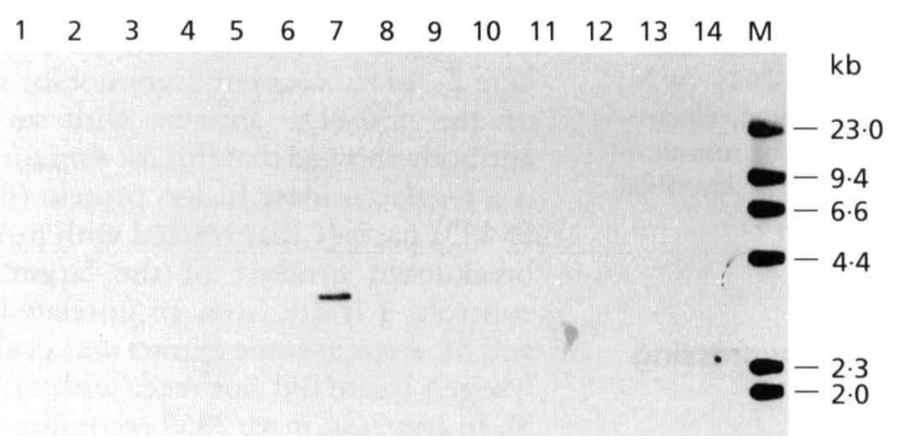

(b)

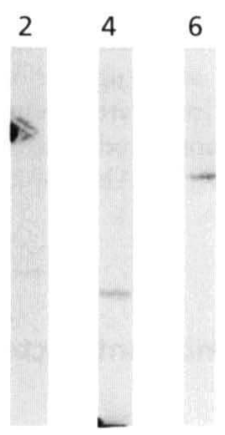

Fig. 2. Southern blot analysis using an MK35 gene probe. (a) Mycobacterial DNA restricted with EcoRI was loaded in the following lanes: $1, M$. asiaticum; $2, M$. avium; $3, M$. bovis; $4, M$. bovis BCG; $5, M$. fortuitum; $6, M$. intracellulare; $7, M$. kansasii; 8, M. phlei; 9, M. scrofulaceum; 10, M. smegmatis; 11, M. terrae; 12, $M$. tuberculosis H37Ra; 13, $M$. tuberculosis H37Rv. HindIIl-restricted DNA molecular mass markers were loaded in lane $M$. (b) Hybridization was detected in the $M$. avium (2), $M$. bovis BCG (4), and $M$. intracellulare (6) lanes with a fivefold extended exposure. 
t tcggqaaatgcaagtatetgaagcacctgaccgcggt agt cgcagt cgcageggtgagc aagcctctacgteatatact cgtggactggcgccatcagcgteagcgtegccactcg

$\begin{array}{llllllllllllll}M & K & \text { H } & \text { L } & T & \text { A } & V & \text { V } & \text { A } & V & \text { A } & \text { A } & V & S\end{array}$

ctggcactggetggttgeggetcaaagaccgaaaccaagacctecacgtcgacgtcgtcg gaccgtgacegaccaacgccgagtetectggettrggttet ggaggegeagetgeagcagc tcgacgagttccacgtcgacaacatccgegtcctcgaccagcgcgacaccgggagcgcag 121 ---1 agctgct caaggt gcagctgttgtaggcgcaggagctggtegggctotggcetcgcgt $\begin{array}{lllllllllllllllllllll}S & T & S & S & T & S & T & T & S & A & S & S & T & S & A & T & P & G & A & 0\end{array}$

181 gccaagaagaccatct ccgactatct caacgagaacaacgtcaccgaaaccecggtccac 24 cggttcttctggtagaggctgatagagttgctcttgttgcagtggctttggggccaggtg $\begin{array}{llllllllllllllllllll}A & K & K & T & I & S & D & Y & L & N & E & N & N & V & T & E & T & P & V & H\end{array}$

etgggegatcecggct egcegaccat caatttgccgat gcccaacggctggcagaccgcc 1 gaccegctagggccgagcggct ggtagt taaacggctacgggttgcegaccgtctggcgg $\begin{array}{llllllllllllllllllll}\text { L } & G & D & P & G & S & P & T & I & N & L & P & M & P & N & G & W & Q & T \cdot A\end{array}$ aacgacagcagcacct catacggcgccatcgtctacagtcagccggecgaccccaaggac gac 360 ttgetgt cgtcgtggagtatgecgcggtagcagat gtcagtcggccggetggggt tcetg $\begin{array}{lllllllllllllllllllll}N & D & S & S & T & S & Y & G & A & I & V & Y & S & Q & P & A & D & P & K & D\end{array}$ ecgcccaccatctccgcactggtctccaaactcaccggcaacgtggacceggcgaagatc

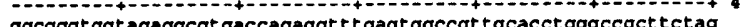

$\begin{array}{llllllllllllllllllll}P & P & T & I & S & A & L & V & S & K & L & T & G & N & V & D & P & A & K & I\end{array}$

atcgagtatgececgggegagctgcagaacetgeccggataccagggttcgggeaacggg $421-210$ $\begin{array}{llllllllllllllllllll}\text { I } & E & Y & A & P & G & E & L & Q & N & L & P & G & Y & Q & G & S & G & N & G\end{array}$ tccgegtccacgctcagcggtt tcaatgcetggcagctgggcggcacctacgtcegcgac aggegeaggtgcgagtcgccaaagttacggaccgt cgacccgccgtggatgcaggcgetg $\begin{array}{llllllllllllllllllll}S & A & S & T & \text { L } & S & G & F & N & A & W & Q & L & G & G & T & Y & V & R & D\end{array}$ ggcaagacccgcgccgtcgcccagaagacggtggtgatccceggt caggacgccgtttac ccgttctgggcgcggcagcgggtcttctgccaccactaggggecagtcctgcggcaato 600 $\begin{array}{lllllllllllllllllllll}G & K & T & R & A & V & A & Q & K & T & V & V & I & P & G & Q & D & A & V & Y\end{array}$ gtgct $t$ cagct caacgccgactcact ggaaagcgagcagggeccgttgat ggatgcgacc 601 - gcttcagctcaacgccgactcactegaaagcgagcage +660 C $Q$ L agcgtcat cgacgagcagaccacgatcacgcagtancgeagtagetggceagcgcctggc 661 - 61 $\begin{array}{llllllllllllllllllll}S & V & I & D & E & Q & T & T & I & T & Q & * & R & S & S & W & P & A & P & G\end{array}$

Fig. 3. Nucleotide sequence and deduced amino acid sequence of the MK35 gene. The putative initiation codon (bp 19-21) and termination codon (bp 694-696) are shown in bold type. A potential ribosome-binding site is underlined at bp 5-9.

deduced amino acid sequence were also analysed using the GCG software package (Devereux et al., 1984). No significant homologies to known non-mycobacterial genes or proteins were found.

\section{The MK35 gene encodes a mycobacterial lipoprotein}

Lipoproteins are among the most immunogenic antigens identified in mycobacteria. We have previously demonstrated that the deduced protein sequences of four known mycobacterial lipoproteins - the 19 and $38 \mathrm{kDa} M$. tuberculosis proteins and the 19 and $27 \mathrm{kDa} M$. intracellulare antigens - have similar amino-terminal sequences (Nair et al., 1992, 1993). A comparison of the MK35 protein sequence with the sequences of the other known mycobacterial lipoproteins revealed the same amino-terminal
1

50

Mi22 $12 .$. VKROLTVAVAGAAI.LAAGISGCSGGNKSGTSASSSASSSGTSA Msgant 19 ......VKRGLTVAVAGAAI.LVAGL,SGCS.SNKSTTGSGETTTAAGTTA Me35 ...... MKHLTAVVAVAAVSLALAGCGSKTETKTSTSTSSSTSSTSTTS Mi43 MSASCAVPRLTREAVFAVAGATALSLSACGSSNKSSSTSTSTSTSTSTVT Msgpaba ...VKIRLHTLLAVLTAAPLLLAAAGCGSKPPSGSPETGAGAGTVATTPA

51200

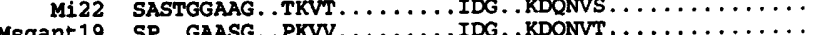

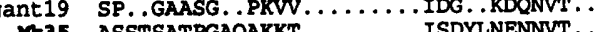

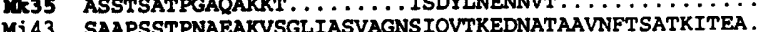

Msgpaba SSPVTLAETGSTLLYPLFNLWGPAFHERYPNVTITAQGTGSGAGIAQAAA

101

gSVVCTNAGg. . TINIAIGga......

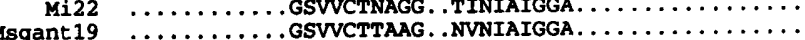

$\ldots \ldots \ldots \ldots \ldots$ ETPVHLGDPGSPINLPMPNGWQTANDSSTSYGAIVYS

MI43 ...VPAGLPDVTOGSCLIVKPTEGSAPGQPVTAAKVKISESVNGTCPKPHE

Msgpaba GTVNIGASDAYLSEGDMAAHKGLMNIALAISAQQVNYNLPGVSEHLKLNG

151 200

Mi22 $151 . \ldots$. ATGIA.......A.AVLSD. .GNPPQVK. SVGLGNVNGVTLGYTS

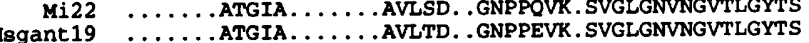

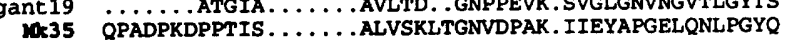

$\begin{array}{ll}m=35 & \text { QPADPKDPPTIS . . . . . . . ALVSKLTGNVDPAK. IIEYAPGELQNLPGYQ } \\ \text { Mi43 STPGGASSTPPS . . . . . GSPSPAPAKPAWVRGSVASVSGDTINLTGTD }\end{array}$

Msgpaba KVLAAMYQGTIKTWDDPQIAALNPGVNLPGTAVVPLHRSDGSGDTFLFTQ

201

250

Mi22 GTGOGNATASKDGNSYKISGT................ VDMANPMQP

Msgant19 GTGOGNASATKDGSHYKITGT.............ATG.VDMANPMSP

035 GSGNGSASTLSGFNAWOLGGTYVRDGKTRAVAOKTVVIPG. ODAVYVLQL

MI

$\begin{aligned} \text { Mi43 } & \text { ASGNTTQTTVTVDDKTKYTKQTTANTEAIAPGKCLSARGT.TDSGGALQA } \\ \text { MSgPaba } & \text { YLSKQDPEGWGKSPGFGTTVDFPAVPGALGENGNGGMVGCAETPGCVAY }\end{aligned}$

251

251

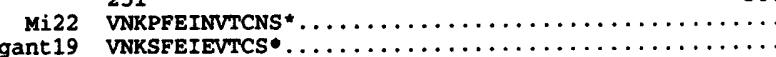

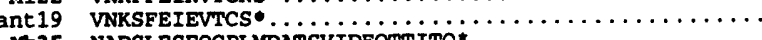

1035 NADSLESEQGPLMDATSVIDEQTTITQ $\ldots \ldots \ldots \ldots \ldots \ldots \ldots$

Mi43 TSIKLRQAVDGKCGKPKQPGQGG * $\ldots \ldots \ldots \ldots \ldots \ldots$

Msgpaba IGISFLDQASQRGLGEAQLGNSSGNFLLPDAQSIQAAAAGFASKTPANQA

Fig. 4. Comparison of the predicted amino acid sequence of the MK35 protein with the sequences of the $M$. intracellulare $19 \mathrm{kDa}$ lipoprotein (Mi22), the $M$. tuberculosis $19 \mathrm{kDa}$ lipoprotein (Msgant19), the $M$. intracellulare $27 \mathrm{kDa}$ lipoprotein (Mi43), and the M. tuberculosis $38 \mathrm{kDa}$ lipoprotein (Msgpaba). The underlined amino acid residues represent the predicted lipoprotein processing sequences. Dots represent gaps in the protein sequences which facilitate alignment of these sequences.

primary sequence similarities (Fig. 4). Each mycobacterial lipoprotein has a sequence motif similar to the prokaroytic consensus sequence for protein lipidation and modification (Wu \& Tokunaga, 1986). For MK35, the proposed lipidation sequence LAGCGS (amino acids 17-22) consists of an invariant cysteine flanked by small neutral amino acids. A hydrophobic region (possibly a signal sequence) precedes the lipidation site in each of these lipoproteins. Eleven of thirteen amino acids in this hydrophobic segment of MK35 (residues 4-16) are either leucine, valine or alanine. The region of the mycobacterial lipoproteins following the consensus lipidation sequence characteristically consists mainly of serines and threonines (Nair et al., 1993a, b). For MK35, 23 of 28 amino acids in this segment (amino acids 23-58) are either serine or threonine.

Triton X-114 extractions of $M$. kansasii sonic extracts were performed to further examine the lipophilic nature of MK35. Proteins strongly associated with membranes (i.e. integral membrane proteins and lipoproteins) will segregate with the Triton X-114 detergent phase upon phase separation. Soluble proteins (i.e. cytoplasmic and loosely associated membrane proteins) will partition into the upper aqueous layer. To determine the detergent 


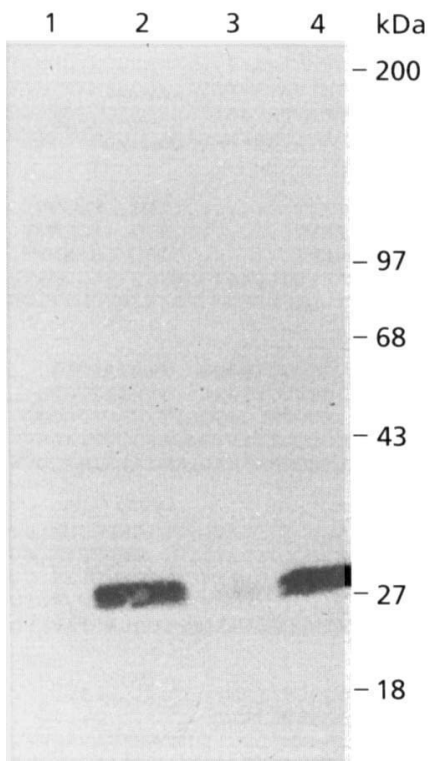

Fig. 5. Immunoblot analysis of Triton $X-114$ extracted sonic extracts. The following samples were resolved by SDS-PAGE and blotted: lane 1, $M$. intracellulare sonic extract; lane 2, $M$. kansasii Triton X-114 detergent phase; lane 3, M. kansasii Triton X-114 aqueous phase; lane $4, M$. kansasii sonic extract. The immunoblot was then incubated with mAb 3869 and developed as described in Methods.

solubility of MK35, M. kansasii sonicates were extracted with Triton $\mathrm{X}-114$ and the phases were separated by incubation at $37^{\circ} \mathrm{C}$. The Triton X-114-soluble and aqueous phases were subjected to SDS-PAGE and then transferred to nitrocellulose. The Western blots were subsequently incubated with $\mathrm{mAb} 3869$. The immunoblot analyses strongly suggested that MK35 is a hydrophobic protein because it partitioned almost completely into the Triton X-114 detergent phase (Fig. 5, lane 2) and was only weakly detected in the aqueous layer (Fig. 5, lane 3). As demonstrated previously, it is apparent from this immunoblot that MK35 migrates anomalously on SDSpolyacrylamide gels (Fig. 5, lane 4). Molecular mass estimates based on these experiments have suggested that MK35 is a $32 \mathrm{kDa}$ protein and not the $26 \mathrm{kDa}$ protein defined by nucleotide sequence analysis of the MK35 gene. This anomalous mobility on SDS polyacrylamide gels is characteristic of mycobacterial proteins modified by lipidation.

\section{DISCUSSION}

One prerequisite for developing improved mycobacterial vaccines and diagnostic reagents is the identification and characterization of novel mycobacterial immunogens. Lipoproteins are among the most immunoreactive antigens derived from bacterial pathogens, including mycobacteria. Bacterial lipoproteins are generally highly immunogenic in vivo and have been implicated as protective antigens for several diseases (Green et al., 1987; Finke et al., 1990; Fikrig et al., 1992). Thus far, the 19 and $38 \mathrm{kDa} M$. tuberculosis proteins and the 19 and $27 \mathrm{kDa} M$. intracellulare antigens have been identified as mycobacterial lipoproteins using genetic and biochemical methods (Young \& Garbe, 1991; Nair et al., 1992, 1993). Each of these proteins induces humoral and cell-mediated immunological responses. In this report, we describe the isolation and characterization of another immunogenic mycobacterial lipoprotein, the MK35 antigen from $M$. kansasii. We have concluded that MK35 is a lipoprotein based on the following data: the deduced amino acid sequence of MK35 has a consensus prokaryotic motif for lipidation, its amino acid sequence is similar to the sequences of known mycobacterial lipoproteins, MK35 has an aberrant electrophoretic mobility, and the MK35 antigen partitions into the detergent-soluble Triton $\mathrm{X}$ 114 extraction phase. Furthermore, we demonstrated that MK35 induced DTH reactions in sensitized guinea pigs. Previously we had shown that MK35 is recognized by sera from AIDS patients with mycobacterial disease (Morris et al., 1991). This immunoreactivity of MK35 in DTH and serological assays is consistent with its classification as a mycobacterial lipoprotein.

Given the limited efficacy of the current mycobacterial vaccine, an international public health priority is the development of a more effective vaccine. The characterization of new mycobacterial immunogens should accelerate vaccine development. Because of the problems associated with a live vaccine, including stability, safety, consistency of production and limited applicability for immunocompromised individuals, it has been suggested that a mycobacterial subunit vaccine would be desirable. Recent studies have shown that a subunit vaccine may be feasible because $M$. tuberculosis culture filtrate proteins are partially protective against an $M$. tuberculosis challenge and vaccination with purified $M$. leprae proteins inhibited $M$. leprae multiplication in mouse footpads (Andersen, 1994; Gelber et al., 1994; Horwitz et al., 1995). The inherent immunogenicity of mycobacterial lipoproteins makes them potential candidates for evaluation as subunit vaccine components. Alternatively, the efficacy of BCG as a mycobacterial vaccine could be enhanced by overexpressing protective antigens in BCG. Stover et al. (1993) have shown that expression of target antigens in BCG as membrane-associated lipoproteins increases the potential to induce protective responses. Therefore, testing the protective capacity of mycobacterial lipoproteins, including $\mathrm{MK} 35$, as recombinant fusion proteins in BCG or a components of a subunit vaccine is warranted.

Because of the increasing importance of mycobacterial disease, there is also considerable interest in the availability of species-specific skin test or serological reagents. The selective and large DTH reactions elicited by MK35 and the seroreactivity of MK35 suggest that this protein, or peptide derivatives of it, may have potential clinical utility as immunodiagnostic reagents for the detection of $M$. kansasii infections in humans. Recent experiments have demonstrated that synthetic peptides designed from the sequences of mycobacterial lipoproteins can yield species-specific DTH responses (Vordermeier et al., 1992; Estrada et al., 1992; Mackall et al., 1993). These studies suggest that the development of species-specific diag- 
nostic reagents consisting of multimeric peptide polymers may be feasible. The availability of species-specific reagents for skin testing or serodiagnosis would possibly permit the rapid differentiation of nontuberculous mycobacterial infections from those caused by $M$. tuberculosis.

\section{REFERENCES}

Andersen, P. (1994). Effective vaccination of mice against Mycobacterium tuberculosis infection with a soluble mixture of secreted mycobacterial proteins. Infect Immun 62, 2536-2544.

Bordier, C. (1981). Phase separation of integral membrane proteins in Triton X-114 solution. J Biol Chem 256, 1604-1607.

Colditz, G. A., Brewer, T. F., Berkey, C. S., Wilson, M. E., Burdick, E., Fineberg, H. V. \& Mosteller, F. (1994). Efficacy of BCG vaccine in the prevention of tuberculosis - meta analysis of the published literature. J Am Med Assoc 271, 698-702.

Collins, M. E., Patki, A., Wall, S., Nolan, A., Goodger, J., Woodward, M. J. \& Dale, J. W. (1990). Cloning and characterization of the gene for the ' $19 \mathrm{kDa}$ ' antigen of Mycobacterium bovis. J Gen Microbiol 136, 1429-1436.

Davies, P. O. D. (1994). Infection with Mycobacterium kansasii. Thorax 49, 435-436.

Devereux, J., Haerberli, P. \& Smithies, O. (1984). A comprehensive set of sequence analyses programs for the VAX. Nucleic Acids Res $12,387-395$.

Dooley, S. D., Jarvis, W. R., Martone, W. J. \& Snider, D. E. (1992). Multidrug-resistant tuberculosis. Ann Intern Med 117, 257-259.

Estrada, I., Guitterez, M., Esparza, J., Quesada-Pascual, F., Estrada-Parra, S. \& Passani, L. (1992). Use of synthetic peptides corresponding to sequences of Mycobacterium leprae to study delayedtype hypersensitivity responses in sensitized guinea pigs. Int J Lepr 60, 18-27.

Fikrig, E., Barthold, S. W., Marcantonio, N., Deponte, K., Kantor, F. S. \& Flavell, R. (1992). Roles of ospA, ospB, and flagellin in protective immunity to Lyme borreliosis in laboratory mice. Infect Immun 60, 657-661.

Fine, P. E. M. \& Rodrigues, L. C. (1990). Modern vaccines mycobacterial diseases. Lancet 335, 1016-1020.

Finke, M., Duchene, M., Eckhardt, A., Domdey, H. \& Von Specht, B. U. (1990). Protection against experimental Pseudomonas aeruginosa infection by recombinant $P$. aeruginosa lipoprotein I expressed in Escherichia coli. Infect Immun 58, 2241-2244.

Gelber, R. H., Mehra, V., Bloom, B., Murray, L. P., Sui, P., Tsang, M. \& Brennan, P. J. (1994). Vaccination with pure Mycobacterium leprae inhibits $M$. leprae multiplication in mouse footpads. Infect Immun 62, 4250-4255.

Green, B. A., Quinn-Dey, T. \& Zlotnik, G. W. (1987). Biologic activities of antibody to a peptidoglycan-associated lipoprotein of Haemophilus infuenzae against multiple clinical isolates of $H$. influenzae type b. Infect Immun 55, 2878-2883.

Horsburgh, C. R. \& Selik, R. (1989). The epidemiology of disseminated nontuberculous mycobacterial infection in the acquired immunodeficiency syndrome (AIDS). Am Rev Respir Dis 139, 4-7.

Horwitz, M. A., Lee, B. W. E., Dillon, B. J. \& Harth, G. (1995). Protective immunity against tuberculosis induced by vaccination with major extracellular proteins of Mycobacterium tuberculosis. Proc Natl Acad Sci, US A 92, 1530-1534.

Kohler, G. \& Milstein, C. (1975). Continuous culture of fused cells secreting antibody of predetermined specificity. Nature 256, 495-497.
Levine, B. \& Chaisson, R. E. (1991). Mycobacterium kansasii: a cause of treatable pulmonary disease associated with advanced human immunodeficiency virus (HIV) infection. Ann Intern Med 114, 861-868.

Lillo, M., Orengo, P., Cernoch, P. \& Harris, R. L. (1990). Pulmonary and disseminated infection due to Mycobacterium kansasii - a decade of experience. Rev Infect Dis 12, 760-767.

Mackall, J. C., Bai, G. H., Rouse, D. A., Armoa, G., Chuidian, F., Nair, J. \& Morris, S. L. (1993). A comparison of the T cell delayedtype hypersensitivity epitopes of the $19 \mathrm{kD}$ antigens from Mycobacterium tuberculosis and Mycobacterium intracellulare using synthetic peptides. Clin Exp Immunol 93, 172-177.

Morris, S. L., Rouse, D. A., Hussong, D. \& Chaparas, S. D. (1988). Isolation and characterization of a recombinant $\lambda$ gt11 bacteriophage which expresses an immunoreactive Mycobacterium intracellulare protein in Escherichia coli. Infect Immun 56, 3026-3031.

Morris, S. L., Rouse, D. A., Hussong, D. \& Chaparas, S. D. (1990). Isolation and characterization of recombinant $\lambda \mathrm{gt} 11$ bacteriophages expressing four different Mycobacterium intracellulare antigens. Infect Immun 58, 17-20.

Morris, S. L., Bermudez, L. \& Chaparas, S. D. (1991). Mycobacterium avium complex disease in patients with AIDS: seroreactivity to native and recombinant mycobacterial antigens. J Clin Microbiol 29, 2715-2719.

Morris, S. L., Nair, J. \& Rouse, D. A. (1992). The catalase-peroxidase of Mycobacterium intracellulare: nucleotide sequence analysis and expression in Escherichia coli. J Gen Microbiol 138, 2363-2370.

Nair, J., Rouse, D. A. \& Morris, S. L. (1992). Nucleotide sequence analysis and serologic characterization of the Mycobacterium intracellulare homologue of the Mycobacterium tuberculosis $19 \mathrm{kDa}$ antigen. Mol Microbiol 6, 1431-1439.

Nair, J., Rouse, D. A. \& Morris, S. L. (1993). Nucleotide sequence analysis and serologic characterization of a 27 kilodalton Mycobacterium intracellulare lipoprotein. Infect Immun 61, 1074-1081.

Reilly, L. W. (1993). Drug resistant tuberculosis. Clin Infect Dis 17(Suppl 2), S442-S446.

Rouse, D. A., Morris, S. L., Karpas, A., Probst, P. G. \& Chaparas, S. D. (1990). Production, characterization, and species specificity of monoclonal antibodies to Mycobacterium avium complex protein antigens. Infect Immun 58, 1445-1449.

Shafer, R. W. \& Sierra, M. F. (1992). Mycobacterium xenopi, Mycobacterium fortuitum, Mycobacterium kansasii and other nontuberculous mycobacteria in an area of endemicity for AIDS. Clin Infect Dis 15, 161-162.

Sheerer, R., Sable, R., Sonnenberg, M., Cooper, S., Spenser, B., Schevimmer, S., Kucha, F., Muthuswamy, P. \& Kallech, C. (1986). Disseminated infection with Mycobacterium kansasii in the acquired immunodeficiency syndrome. Ann Intern Med 105, 710-712.

Shinnick, T. M., Plikaytis, B. B., Hyche, A. D., Van Landinham, R. M. \& Walker, L. L. (1989). The Mycobacterium tuberculosis BCG A protein has homology with the Escherichia coli groES protein. Nucleic Acids Res 17, 1254.

Stover, C. K., Bansal, G. P., Hanson, M. S., Burlein, J. E., Palaszynski, S. R., Young, J. F., Koenig, S., Young, D. B., Sadziene, A. \& Barbour, A. G. (1993). Protective immunity elicited by recombinant Bacille Calmette-Guerin (BCG) expressing outer surface protein A (OspA) lipoprotein: a candidate Lyme disease vaccine. $J$ Exp Med 178, 197-209.

Studier, F. W. \& Moffat, B. W. (1986). Use of bacteriophage T7 RNA polymerase to direct selective high-level expression of cloned genes. J Mol Biol 189, 113-130.

Vordermeier, H. M., Harris, D. P., Mehrota, P. K., Roman, E., 
Elsaghier, A. \& Ivanyi, J. (1992). M. tuberculosis complex specific Tcell stimulation and DTH reactions induced with a peptide from the $38 \mathrm{kDa}$ protein. Scand J Immunol 35, 711-718.

Wallace, R. J., O'Brien, R., Glassroth, J., Raleigh, J. \& Dutt, A. (1990). Diagnosis and treatment of disease caused by nontuberculous mycobacteria. Am Rev Respir Dis 142, 940-953.

Wu, H. C. \& Tokunaga, M. (1986). Biogenesis of lipoproteins in bacteria. Curr Top Microbiol Immunol 125, 127-157.
Young, D. B. \& Garbe, T. R. (1991). Lipoprotein antigens of Mycobacterium tuberculosis. Res Microbiol 142, 55-65.

Young, L. S., Inderlied, C. B., Berlin, O. G. \& Gottlieb, M. S. (1986). Mycobacterial infections in AIDS patients with an emphasis on the Mycobacterium avium complex. Rev Infect Dis 8, 1024-1033.

Received 15 February 1995; revised 23 May 1995; accepted 5 June 1995. 